\title{
Forenklet elektrofysiologisk undersøkelse ved hjertebankanfall
}

\author{
Sammendrag \\ Bakgrunn. Ubehag av unormalt hurtig \\ puls eller hjertebank forekommer \\ relativt hyppig. Klinisk diagnostisering \\ av hjertebank har lav sensitivitet, og \\ pasienter uten korrekt diagnose får \\ som regel ikke behandling.
}

Materiale og metode. Resultatene fra langtids-EKG-undersøkelser for perioden 1.8. 2004-31.7. 2005 ved Sykehuset Telemark ble gjennomgått. Av totalt 614 undersøkelser var 252 utført på indikasjonen hjertebank og palpitasjoner. Indikasjonsstillinger og beskrivelser av undersøkelsene ble funnet i elektroniske prosedyrelister og journaler. 137 pasienter uten avklart diagnose ble invitert til en forenklet invasiv elektrofysiologisk undersøkelse hvor hjertet ble stimulert med en pacemakerelektrode i høyre atrium. 39 av disse pasientene ble funnet inkluderbare og gjennomgikk undersøkelsen. En pasient ønsket å trekke sine data. Ytterligere 18 pasienter ble på samme utvalgskriterier undersøkt elektrofysiologisk. Materialet omfattet totalt 56 pasienter.

Resultater. Ved hjelp av langtids-EKG fant man den avklarende diagnosen hos 29 pasienter med hjertebank og palpitasjoner. Forenklet elektrofysiologisk undersøkelse avdekket reentrytakykardi hos ni pasienter og paroksysmal atrieflutter hos tre. Totalt ble det gjennomført 56 elektrofysiologiske undersøkelser, der man avdekket 12 tilfeller av abladerbar takykardi. To pasienter måtte elektrokonverteres, for øvrig forløp prosedyren komplikasjonsfritt.

Fortolkning. Forenklet elektrofysiologisk undersøkelse vil i denne pasientgruppen avdekke takykardi som kan abladeres hos om lag $20 \%$ av de undersøkte. Dette vil resultere i en $64 \%$ $\varnothing$ kning i diagnostikk av supraventrikulær takykardi.

\author{
Jan Hysing \\ jan.hysing@sthf.no \\ Medisinsk avdeling \\ Sykehuset Telemark \\ 3710 Skien
}

\section{Harald Brunvand}

Medisinsk avdeling

Sørlandet Sykehus Arendal

De siste 15 år har det foregått en betydelig teknologisk utvikling innenfor medisinsk elektrofysiologi. Vi har i dag et behandlingstilbud for de fleste regelmessige supraventikulære arytmier, som Wolff-Parkinson-Whites syndrom, atriovetrikulær nodal reentrytakykardi og atrieflutter $(1,2)$. Radiofrekvensablasjon er for disse sykdomsgruppene en rutinemessig lavrisikoprosedyre med meget gode resultater. I Norge utføres denne prosedyren ved fire universitetssykehus hos dem som ved EKGundersøkelse har fått dokumentert en definert arytmi.

Da vi nå kan tilby et bedre behandlingsalternativ enn tidligere for disse lidelsene, bør man også ha et bedre diagnostisk tilbud til pasientene. Gjentatte anfall med vedvarende hurtig hjertebank kan for noen være plagsomt og ha en betydelig negativ innflytelse på livskvaliteten både yrkesmessig og sosialt. Mange kan bli skremt av anfallene og få forsterkede angstsymptomer dersom de ikke får noe godt svar på hva hjertebanken skyldes. Videre kan rytmeforstyrrelsen i sjeldne tilfeller skyldes en potensielt farlig ventrikkeltakykardi.

Ved utredning av hjertebankanfall er det vanlig med grundig anamnese, 12-kanalsEKG og langtids-EKG i form av 24-timersEKG-registrering eller sjudagers anfallsEKG (R-test). Alle disse tiltakene har lav sensitivitet, og sannsynligheten for at en sann hjerterytmeforstyrrelse blir påvist, kan være under $30 \%(3-6)$.

En fullverdig elektrofysiologisk undersøkelse gjennomføres med bruk av fire paceelektroder og stimulering av både høyre ventrikkel og høyre atrium. Ved en forenklet elektrofysiologisk undersøkelse gjøres en stimulering bare i høyre forkammer. Vurdert ut fra hyppigheten av de vanligste hjerterytmeforstyrrelsene og hvorledes disse lar seg utløse, burde det være mulig å frembringe over $90 \%$ av alle utløsbare supraventrikulære arytmier med denne metoden (7-10).

Ved Sykehuset Telemark ønsket vi å kartlegge omfanget av fenomenet uavklart hjer- tebank. Videre ville vi undersøke om en forenklet elektrofysiologisk undersøkelse kunne bidra til å avklare diagnosen.

\section{Materiale og metode}

For kartlegging av problemets omfang ble det ved Sykehuset Telemark for perioden fra 1.8. 2004-31.7. 2005 ved hjelp av elektroniske prosedyrelister gjort en registrering av alle langtids-EKG-undersøkelser (24-timers-EKG og R-test) som hadde vært gjennomført. Etter registreringen ble indikasjonsstilling og resultatet av undersøkelsen innhentet fra pasientenes elektroniske journaler.

Tre inklusjonskriterier måtte være oppfylt for videre deltakelse med forenklet elektrofysiologisk undersøkelse: alder 18-75 år, symptomer og sykehistorie som kunne tyde på paroksysmal regelmessig takykardi og manglende funn av regelmessig takykardi, atrieflimmer eller atrieflutter ved gjennomført langtids-EKG (24-timers-EKG eller Rtest). I tillegg måtte de som skulle delta i forenklet elektrofysiologisk undersøkelse gi skriftlig informert samtykke.

De som i henhold til resultater fra langtids-EKG og journal syntes å oppfylle inklusjonskriteriene, ble tilskrevet (en gang, uten purring) med en orientering om muligheten for å få utført en forenklet elektrofysiologisk undersøkelse. De fikk også invitasjon til en legekonsultasjon for å få avklart hvorvidt en slik undersøkelse kunne være ønskelig. I forbindelse med informasjonssamtale og legeundersøkelse ble det gjennomført et åpent intervju i tillegg til et strukturert (i form av besvaring av et spørreskjema). For å samle økt erfaring med metoden videreførte vi tilbudet om forenklet elektrofysiolo-

\section{Hovedbudskap}

- I Telemark ble det på ett år gjort 233 langtids-EKG-unders økelser med indikasjon hjertebank per 100000 innbyggere

- Langtids-EKG har en begrenset sensitivitet for å fange opp paroksysmal supraventrikulær takykardi

- Forenklet elektrofysiologisk unders $\varnothing$ kelse kan øke muligheten for korrekt diagnostisering av arytmi tidligere

- Forenklet elektrofysiologisk unders $\varnothing$ kelse lar seg utføre uten alvorlige komplikasjoner ved et områdesykehus 
gisk undersøkelse til pasienter i Telemark og Aust-Agder, etter samme utvalgskriterier som vi brukte i studien av ettårsmaterialet, for perioden august 2005 ut februar 2006 (tilleggsmaterialet)

Stimuleringsprotokollen for forenklet elektrofysiologisk undersøkelse var utarbeidet i samarbeid med elektrofysiologisk enhet, Hjertemedisinsk avdeling, Oslo universitetssykehus, Rikshospitalet. Den ble gjennomført med lokalanestesi og steril kanylering av v. femoralis med Seldinger-teknikk og en 7 french $(\mathrm{F})$ introduserhylse. En $6 \mathrm{~F}$ kvadripolær elektrode ble under giennomlysing plassert med elektrodeenden lateralt høyt i høyre artium. Paceterskelen ble bestemt med $2 \mathrm{~ms}$ impulsbredde. Den videre elektrofysiologiske stimuleringen ble utført med dobbelt voltstyrke av paceterskelen.

Stimuleringsprotokollen besto av åtte regelmessige paceimpulser med $600 \mathrm{~ms}$ intervaller, for å synkronisere hjertets repolarisasjon, fulgt av en ekstraimpuls (ekstrasystole som fremprovoserer en alternativ ledingsbane i det refraktære myokard). Intervallet mellom siste regelmessige impuls og ekstrasystolen ble så suksessivt redusert fra 600 ms til $200 \mathrm{~ms}$. Dette ble gjentatt med $400 \mathrm{~ms}$ mellom de åtte regelmessige impulsene. Deretter ble seriene gjentatt med to ekstraimpulser, og så gjentatt etter infusjon med isoprenalin.

Undersøkelsen ble avbrutt og betegnet som positiv dersom det ble utløst regelmessig smalkomplekset takykardi eller hurtig atrieflimmer. 12-kanalers EKG fra hele undersøkelsen ble lagret elektronisk, og diagnostiske funn ble kvalitetssikret av overlege ved Rikshospitalet. Undersøkelsesprotokollen til denne studien var før oppstart godkjent av regional etisk komité og Norsk samfunnsvitenskapelig datatjeneste (NSD). Studien er registrert i $w w w$.clinicaltrials.gov nr. NCT00251121.

\section{Resultater}

\section{Forekomst}

Ved Sykehuset Telemark ble det i ettårsperioden utført 614 langtids-EKG-unders $\varnothing$ kelser. Indikasjonsstilling og resultater av disse fremgår av tabell 1. De vanligste henvisningsårsaker til langtids-EKG i ettårsmaterialet var utredning for palpitasjoner og hjertebank ( $\mathrm{n}=252,41 \%)$, utredning av synkope $(\mathrm{n}=167,27 \%)$ og spørsmål om atrieflimmer $(\mathrm{n}=129,21 \%)$. Andre indikasjonsstillinger for undersøkelsen og resultater er også presentert $\mathrm{i}$ tabell 1. LangtidsEKG for indikasjonsstillingen palpitasjoner og hjertebank var utført hos 228 pasienter, til sammen 252 undersøkelser. Det ble påvist regelmessig supraventrikulær takykardi hos 11 pasienter, ekstrasystoli hos 11 og atrieflimmer hos 17.

Av de 228 pasientene i ettårsmaterialet som kunne være aktuelle for studien, var det 30 som ikke fylte alderskriteriene, 22 som ikke hadde typisk vedvarende takykardi og
39 der det var gjort avklarende funn på langtids-EKG. Av pasientene i ettårsmaterialet ble 137 personer i alderen 18-75 år tilskrevet med tilbud om en slik konsultasjon. Av de tilskrevne pasientene responderte 51 $(37 \%)$ og møtte til videre samtale. Etter grundig anamneseopptak, strukturert intervju, ekkokardiografisk undersøkelse og informasjonssamtale fant vi i ettårsmaterialet 39 pasienter som det var aktuelt å tilby forenklet elektrofysiologisk undersøkelse. Disse ga skriftlig informert samtykke til deltakelse i studien. 12 pasienter oppfylte ikke inklusjonskriteriene. Årsakene til dette var enten hjertebank av kun sekunders varighet eller fordi de ikke ønsket å gjennomgå den invasive prosedyren. En av dem som ble undersøkt, ønsket å trekke sine data fra undersøkelsen.

I den utvidede delen av studien undersøkte vi 18 pasienter (her betegnet som «tilleggsmaterialet») med forenklet elektrofysiologisk undersøkelse.

\section{Forenklet elektrofysiologisk undersøkelse}

Hos 38 pasienter i ettårsmaterialet ble det gjennomført forenklet elektrofysiologisk undersøkelse i henhold til protokollen. Det ble funnet fem tilfeller av regelmessig reentrytakykardi og to tilfeller av atrieflutter velegnet for enkel radiofrekvensablasjon hos disse. Videre ble det funnet to tilfeller av atrietakykardi med mulig potensial for slik behandling.

56 forenklede elektrofysiologiske undersøkelser ble gjennomført totalt, iberegnet tileggsmaterialet. Median alder hos de undersøkte var 53 år, og hos alle var det normale funn ved ekkokardiografisk undersøkelse. Det ble det funnet 12 tilfeller $(21 \%)$ av regelmessig takykardi som potensielt kunne egne seg for radiofrekvensablasjon: atrioventrikulær nodal reentrytakykardi hos ni og atrieflutter hos tre. Tre pasienter hadde en atrietakykardi hvor muligheten for ablasjon var mer usikker. Det ble videre hos fem pasienter funnet sannsynlig paroksysmal atrieflimmer. Hos ti pasienter ble det utløst uspesifikk kortvarig atrieflimmer som ikke kunne tillegges videre diagnostisk betydning. Resultatene fra de 56 undersøkelsene er fremstilt i tabell 2.

Det var ingen komplikasjoner i form av blødninger eller perforasjoner forbundet med undersøkelsen, men to pasienter måtte elektrokonverteres i narkose for å gjenvinne sinusrytme før hjemreise. I det videre forløp ble åtte pasienter vellykket radiofrekvensbehandlet etter full elektrofysiologisk undersøkelse ved Rikshospitalet. Det var ingen komplikasjoner ved disse prosedyrene. De resterende positive ønsket medikamentell behandling eller å avvente behandling. En pasient med negativt resultat av forenklet elektrofysiologisk undersøkelse fikk dokumentert supraventrikulær takykardi på EKG hos bedriftshelsetjenesten og fikk siden utført radiofrekvensablasjon.

\section{Pasientintervjuene}

Resultatene fra pasientintervjuene avdekket at median symptomvarighet forut for undersøkelsen var 30 måneder. 33 av 56 svarte at anfallene inntraff fra flere ganger $\mathrm{i}$ uken til noen ganger per måned. Videre svarte $36 \mathrm{av}$ 56 at anfallsvarigheten var fra minutter til opptil ett døgn. Fire av pasientene kunne fortelle om gjentatte anfall med betydelig ubehag og påfølgende angst og sosiale hemninger. Tre pasienter var indignert eller fortvilet over at helsevesenet ikke klarte å stille noen diagnose og at man karakteriserte plagene som funksjonelle eller psykisk betinget. To hadde opplevd synkope på arbeidsplassen i forbindelse med hjertebankanfallene, og en var på grunn av sikkerhetsmessige forhold rundt dette blitt oppsagt fra sitt arbeid.

\section{Diskusjon}

Vi kunne med forenklet elektrofysiologisk undersøkelse finne arytmier velegnet for radiofrekvensablasjonsbehandling hos 12 av 56 undersøkte. Som supplement til diagnostikken ved langtids-EKG økte vi det diagnostiske utbyttet for radiofrekvensablasjonsegnede arytmier i ettårsmaterialet fra 11 til 18 (fra 4,4\% til 7,1\%). De observerte funn etter 56 undersøkelser avslører en liknende tendens.

Fra henvisningene til langtids-EKGundersøkelse i ettårsmaterialet får vi et bilde av hvor mange som utredes for hjertebank. Sykehuset Telemark er lokalsykehus for en populasjon på 108000 mennesker, og det ble ukentlig i gjennomsnitt utført fem langtids-EKG-undersøkelser på indikasjonen palpitasjoner og hjertebank. Ut fra klinisk erfaring og andre studier (3-6) er det sannsynlig at man ved hjelp av langtids-EKG bare kan påvise en brøkdel av de abladerbare arytmiene. Vår studie bekrefter tidligere erfaringer og undersøkelser når det gjelder den lave sensitiviteten ved langtids-EKG. For den videre utredning av disse pasientene blir det således en utfordrende oppgave å avgjøre hvor mye ressurser som skal brukes.

Et grundig anamneseopptak er det viktigste diagnostiske enkelttiltak ved utredning av takykardi (11). Gjennom pasientintervjuene kom det frem at det $\mathrm{i}$ mange av henvisningene ikke var differensiert klart nok mellom følelsen av kortvarige palpitasjoner eller urolig hjerte og vedvarende hjertebank med hurtig puls over tid. Videre kom det frem at hyppigheten av anfallene varierte over tid og for manges vedkommende gikk over av seg selv. Når bare 51 av 138 pasienter som var uten diagnose responderte på vårt brev med invitasjon til videre elektrofysiologisk utredning, gjenspeiler dette kanskje at hjertebank hos to av tre ikke blir opplevd som noe stort og vedvarende helseproblem. En supraventrikulær takykardi hos den som ikke har annen hjertesykdom, utgjør sjelden noen mortalitetsrisiko $(4,11)$.

Intervjuene avdekket likevel at supraventrikulær takykardi for noen kan nedsette 
Tabell 1 Spørsmålsstilling, og funn ved langtids-EKG (24-timers-EKG og R-test), et ettårsmateriale (1.8. 2004-31.7. 2005)

\begin{tabular}{|c|c|c|c|c|c|c|}
\hline Henvisningsårsak & Antall undersøkelser & $\begin{array}{l}\text { Supraventrikulær } \\
\text { takykardi }\end{array}$ & Ekstrasystoli & Atrieflimmer & $\begin{array}{l}\text { Blokkeringer } \\
\text { og pauser }\end{array}$ & Ventrikkeltakykardi \\
\hline Hjertebank & 252 & 11 & 11 & 17 & & \\
\hline Synkope & 167 & 5 & & 8 & 22 & 3 \\
\hline Atrieflimmer & 129 & & & 73 & & \\
\hline Angina pectoris & 20 & 1 & & & 1 & \\
\hline Ventrikkeltakykardi & 18 & & & & & 1 \\
\hline Førerkortutredning & 14 & & & 1 & & 1 \\
\hline Asteni & 13 & & & 2 & 3 & \\
\hline
\end{tabular}

livskvaliteten betydelig. Til tross for at kurativ behandling finnes, kan enkelte være svært plaget av lidelsen over tid fordi riktig diagnose ikke blir stilt. Vi mener at plagene og hvordan pasienten opplever det å ha hjertebank må være avgjørende for videre henvisning og for strategi for utredningen. Dersom symptomene vedvarer og pasienten har mye plager, synes gjentatte langtidsEKG-udersøkelser med nøyaktig aktivitets$\operatorname{logg}$ å være første tiltak $(11-13)$. Størst sjanse for å fange opp arytmi vil man ha ved implantasjon av en rytmeovervåker (loop recorder) som pasientene går med under huden i opptil 18 måneder $(3-6,13)$. På grunn av prisen og de nødvendige operasjoner mener vi at dette i praksis ikke er noe realistisk alternativ i utredningen av mistenkt supraventrikulær takykardi hos personer uten annen kjent hjertesykdom.

Et nytt ambulant, pasientaktivert produkt, kalt «rytmekort» (Metec/Instromedix), som pasientene selv legger på brystet når de får hjertebank, har også vist seg nyttig (12). Nytten ligger her også $i$ at man hos mange får dokumentert normal sinusrytme under det som subjektivt oppfattes som hjertebankanfall. Dette tilbudet finnes i dag bare ved et fåtall sykehus. Hos noen pasienter med sterke og vedvarende plager hvor man etter gjentatte langtidsregistreringer fortsatt har begrunnet mistanke om udiagnostisert supraventrikulær takykardi som burde kunne behandles, bør fullverdig elektrofysiologisk undersøkelse være indisert (11). Tilbudet om dette varierer og er til dels sterkt begrenset.

Tabell 2 Funn ved forenklet elektrofysiologisk undersøkelse av 56 pasienter med hjertebank og negativt resultat av langtids-EKG

\begin{tabular}{lc} 
Type takykardi påvist & Antall funn (\%) \\
\hline $\begin{array}{l}\text { Ingen patogiske funn } \\
\text { Atrieventrikulær nodal } \\
\text { reentrytakykardi }\end{array}$ & $23(41)$ \\
\hline Langvarig atrieflimmer & $9(16)$ \\
\hline Fokal atrietakykardi & $5(9)$ \\
\hline Atrieflutter & $3(5)$ \\
\hline $\begin{array}{l}\text { Kortvarig atrieflimmer } \\
\text { luspesifikt funn) }\end{array}$ & $3(5)$ \\
\hline
\end{tabular}

Ved en fullverdig elektrofysiologisk undersøkelse vil man ut fra metodens overlegenhet finne arytmier hos en større prosentandel av pasientene enn hva vi fant ved vår forenklede prosedyre. Eksempelvis nevnes at skjult Wolff-Parkinson-Whites syndrom, som finnes hos $3-7 \%$ av dem med supraventrikulær takykardi, er en tilstand som ikke lar seg utløse fra høyre atrium (6-9). Realiteten er at svært få pasienter uten dokumentert takykardi får tilbud om å få utført dette ved et universitetssykehus (anslagsvis ved $1 \%$ av prosedyrene, F. Hegbom, personlig meddelelse).

En forenklet elektrofysiologisk undersøkelse med en elektrode $\mathrm{i}$ høyre atrium er på mange vis en undersøkelse analog til stimulering av atriene via oesophaguselektrode (14). Meget gode resultater med oesophaguspacing har tidligere vært rapportert $\mathrm{i}$ Tidsskriftet (15). Ulempen er imidlertid at man med denne metoden må bruke høyere energi ved stimuleringen, noe som ofte er ubehagelig for pasienten. Pasientene må under denne prosedyren ofte sederes med morfin og diazepam. På den annen side slipper man ved oesophaguspacing den transvenøse kanyleringen av hjertet, noe som kan oppfattes som teknisk enklere og mindre risikabelt. Elektrodeperforasjon og perikardeffusjon samt lokale innstikksblødninger er sjeldne, men mulige komplikasjoner til invasiv elektrofysiologisk undersøkelse.

Antallet elektrofysiologiske undersøkelser i vår studie er begrenset. Våre resultater er likevel konsistente med dem man finner i litteraturen, som indikerer lav sensitivitet av langtids-EKG for arytmier. I studier hvor 24-timers-EKG er validert opp mot implantert rytmeovervåker, finner man en sensitivitet av 24-timers-EKG i området $25-38 \%$ (3-6). Økt erfaring med den forenklede elektrofysiologiske metoden, økt volum og skjerpet pasientseleksjon er faktorer som sannsynligvis ville bedre det diagnostiske utbyttet av forenklet undersøkelse ytterligere. Vår studie viser likevel at forenklet elektrofysiologisk undersøkelse godt kan gjennomføres ved et områdesykehus med akseptabelt diagnostisk utfall uten at pasienten påføres vesentlig ubehag eller komplikasjoner. Således kan dette være et tilbud til pasienter med betydelige plager som ellers knapt vil fått noe tilbud om full undersøkelse. Vi vil anbefaler at flere sykehus, slik det ble gjort i vår studie, samarbeider om henvisninger og utredninger slik at de sykehusene som tar i bruk prosedyren har et visst volum og regelmessig aktivitet. Slik ressurssituasjonen er innenfor dette feltet, vil det i uoverskuelig fremtid fortsatt være et stort udekket behov for elektrofysiologisk utredning.

\section{Konklusjon}

Sykehus og spesialistpoliklinikker utfører hvert år et betydelig antall utredninger av hjertebank, palpitasjoner og takykardianfall. I vår undersøkelse i Telemark utgjorde dette 233 per 100000 innbyggere årlig. LangtidsEKG-undersøkelse som R-test og 24-timersEKG ga en diagnostisk avklaring i $10-15 \%$ av tilfellene, og hos $5 \%$ av pasientene ble det funnet arytmier som var egnet for radiofrekvensablasjon. Ved forenklet elektrofysiologisk undersøkelse for et utvalg av pasientene kunne diagnosen abladerbar arytmi stilles hos $20 \%$ av de undersøkte, det tilsvarer en økning på $64 \%$. Så lenge tilgangen på full elektrofysiologisk utredning er svært begrenset, kan prosedyren, på samme måte som oesophaguspacing, utført ved et områdsykehus være et alternativ.

Arbeidet med studien ble støttet økonomisk av Forskningsfondet Sykehuset Telemark. Prosedyrerelatert arbeid ble gjennomført under førsteforfatters avtalebestemte fordypningspermisjon som overlege. Vi takker Rolf Franck Berntsen for hjelp med utarbeiding av protokollen for elektrofysiologisk stimulering og for kvalitetssikring av funnene ved undersøkelsen.

Oppgitte interessekonflikter: Jan Hysing har mottatt støtte til kurs og konferansereiser fra AstraZenica, MSD, Pfizer, Sanofi-Synthelabo, ScheringPlough, Sanofi-Aventis, Merck Serrano og Guidant. Harald Brunvand har ingen oppgitte interessekonflikter.

\section{Litteratur}

1. Vislie $\mathrm{CH}$, Mikkelsen RB, Hoff PI et al. Atrioventrikulær nodal takykardi hos barn. Tidsskr Nor Lægeforen 2006; 126: 2373-6.

2. Chen J, Ohm OJ, Hoff Pl et al. Atrieflutter - diagnostikk og behandlingsmuligheter. Tidsskr Nor Lægeforen 2001; 121: 931-4. 
3. Huikuri HV Raatikainen MJ, Jörgensen RM et al. Prediction of fatal or near-fatal ventricular tachyarrhythmias in patients with depressed left ventricular function after myocardial infarction: the CARISMA study (ESC Congress 2007. Abstract Supplement, Poster P545.) Eur Heart Journal 2007; 28 (suppl): 67.

4. Giada F, Gulizia M, Francese M et al. Recurent unexplained palpitation (RUP) study. Comparison of implantable loop recorder versus conventional diagnostic strategy. J Am Coll Cardiol 2007; 49: $1951-6$.

5. Krahn AD, Klein GJ, Yee R et al. Randomized assessment of syncope trail. Conventional diagnostic testing versus a prolonged monitoring strategy. Circulation 2001; 104: 46-51.

6. Reiffel JA, Schwarzberg R, Murry M. Comparison of autotriggered memory loop recorders versus standard loop recorders versus 24-hour Holter monitors for arrhytmia detection. Am J Cardiol 2005; 95: 1055-9.

7. Schilling RJ. Which patient should be referred to an electrophysiologist: supraventricular tachycardia. Heart 2002; 87: 299-302

8. Orejarena LA, Vidaillet H, DeStefano F et al. Paroxysmal supraventricular tachycardia in the general population. J Am Coll Cardiol 1998; 31 . $150-7$.
9. Goudevenos JA, Katsouras CS, Graekas G. Ventricular pre-excitation in the general population: a study on the mode of presentation and clinical course. Heart 2000; 83: 29-30.

10. Sano S, Komori S, Amano T et al. Prevalence of ventricular preexcitation in Japanese schoolchildren. Heart 1998; 79: 374-8.

11. Zimetbaum $P$, Josephson ME. Evaluation of patients with palpitations. N Engl J Med 1998; 338: 1369-73.

12. Funk M, Chrostowski VM, Richards S et al. Feasibility of using ambulatory electrocardiographic monitors following discharge after cardiac surgery. Home Healthc Nurse 2005; 23: 441-9.

13. Christiansen CS, Gjesdal K. Implanterbar rytmeovervåker ved utredning av synkope. Tidsskr Nor Lægeforen 2007; 127: 1657-9.

14. Kesek M, Sheikh H, Bastani $\mathrm{H}$ et al. The sensitivity of transesophageal pacing for screening in atrial tachycardias. Int J Cardiol 2000; 72: 239-42.

15. Haaland HH, Morstøl TH, Vegsundvåg J et al. Diagnostisk atriestimulering via oesophagus. Tidsskr Nor Lægeforen 2003; 123: 2577-9.

Manuskriptet ble mottatt 28.12. 2008 og godkjent 24.9. 2009. Medisinsk redaktør Odd Terje Brustugun. 